\title{
МОДЕРНИЗАЦИЯ УКРАИНСКОГО ОБЩЕСТВА КАК ИМПЕРАТИВ СОЦИАЛЬНОЙ ЭВОЛЮЦИИ
}

\begin{abstract}
Рассматривается феномен модернизации как макропроцесс перехода от традиционного общества к модерному и постиндустриальному, предполагающий полную или частичную реконструкцию общественной системы с целью ускорения развития; как комплекс взаимосвязанных экономической, политической, социальной и культурной сфер общественной жизни, модернизационные преобразования проявляется в виде появления новых ценностных норм и исчезновения старых. Охарактеризованы два основных типа модернизации - органическая и неорганическая, каждая из которых имеет ограничение во времени, проектную логику и определенного субъекта и выгодоприобретателя, а также два основних подхода, в контексте которых воспринимается и оценивается процесс модернизации: линеарностадиональный (формационный) и цивилизационный. Обосновывается, что социокультурная ситуация современного мира характеризируется наличием силового модернизационного поля, которое притягивает и подталкивает другие страны к либерально-демократической модели общественного развития.

Раскрываются составляющие модернизационной парадигмы современной Украины, доказывается необходимость переориентации украинского модернизационного проекта на европейские ценности с сохранением национальной специфики, учета социокультурных особенностей трансформирующегося общества. Главное назначение украинской модернизации - это создание современного общества, современных социальных институтов и инфраструктуры, восстановление сознания своей «современности», формирование гражданина-патриота с инновационным мировоззрением, мышлением, культурой. Делается вывод о том, что проблемы, перед решением которых Украина остановилась в своем развитии, не сводятся исключительно к экономическим; это проблемы более системного порядка проблемы несформированности украинского общества. Поэтому реформирование экономических отношений, обеспечение их стабильно сбалансированной динамики, как и придание принципиально новых импульсов социальным преобразованиям, возможны лишь на качественно новой основе - на основе мировоззренческой консолидации украинского общества, его осовременивания, модернизации, утверджения либеральных ценностей развития и демократии.

Ключевые слова: национальные ценности, модернизация, догоняющая модернизация, глобализация, идентичность, культурная идентичность, национальная идентичность, украинское общество
\end{abstract}

${ }^{1}$ Prof. Николай Адамович Козловец, доктор философских наук, профессор, заведующий кафедрой философии. Житомирского государственного университета имени Ивана Франко Житомир, Украина, e-mail: nikola_kos@mail.ru 
Глобализация приводит к распространению современных технологий в обществах, которые остаются в эволюционном плане отсталыми, как Бразилия, Россия, Индия, Китай или же Украина. Создается впечатление, что эти общества модерные, хотя на самом деле несколько обновленная в них современная материальная техника сосуществует с устаревшей, примитивной социальной системой. Поэтому все более очевидной становится необходимость глубокого анализа происходящих в Украине перемен.

Теория «модернизации», возникшая в 50-60-х гг. ХХ в. в лоне университетской науки США под влиянием работ Т. Парсонса и Р. Мертона, была создана американскими специалистами по странам «третьего мира» (С. Липсет, Ф. Риггс, Д. Энтер, Р. Уарт, С. Хантингтон и др.) для объяснения происходящих там процессов, взрывающих традиционный порядок и способствующих переходу этих стран к индустриальному и демократическому обществу. Позднее данная теория была взята на вооружение США и другими западными государствами для обоснования их политики в отношении стран Азии, Африки, отчасти Латинской Америки. После исторического поражения коммунизма и распада СССР объектами изучения теории модернизации стали и постсоветские республики.

Модернизация (франц. modernization-обновление) в историософском значении - это макропроцесс перехода от традиционного общества к модерному, от аграрного-к индустриальному, процесс полной или частичной реконструкции общественной системы с целью ускорения развития. Модернизированное общество имеет комплекс взаимосвязанных черт, которые часто рассматриваются как отдельные процессы экономической, политической, социальной и культурной модернизации. Модернизация всех сфер общественной жизни проявляется в виде появления новых ценностных норм и исчезновения старых.

Различают два основных типа модернизации - органическую и неорганическую. Органическая модернизация подготавливается внутренней эволюцией общества, происходит благодаря ресурсам собственного развития и начинается не с экономики, а с изменений культуры, общественного сознания, ментальности, мировоззрения. Например, переход Англии от феодализма к капитализму в результате промышленной революции XVIII в. Капитализм в этом случае стал естественным следствием изменений в традициях, ориентациях, мыслях людей. Органической модернизации свойственны имманентные закономерности и творческий поиск путей усовершенствования политической, экономической, культурной и социальной жизни общества, а развитие происходит в форме непрерывного эволюционного, реформационного процесса.

Неорганическая модернизация обусловлена не внутренними, а внешними факторами и является ответом на вызов со стороны более развитых стран. Она начинается не в сфере культуры, а в экономике и/или политике и осуществляется преимущественно путём заимствования чужих технологий и форм организации производства и общества, привлечения инвестиций, приглашения иностранных специалистов, обучения кадров за границей. Итогом её является не столько совокупность качественных изменений общества, сколько усвоение технологических достижений Запада. Неорганическая модернизация является своеобразной реакцией на достижения развитых стран, формой «догоняющего развития» с целью преодоления исторического отставания и характеризируется 
неравномерностю изменений в экономике, политике, культуре, социальных отношениях. Например, Россия неоднократно пыталась догнать развитые страны (петровские реформы XVIII в., индустриальная модернизация 30-50-х гг. XX в., перестройка 1985 г.) $)^{2}$.

Не каждая модернизация инновационна по своей сути: большинство индустриальных модернизаций в XIX-XX веках носили догоняющий характер и были направлены на достижение уровня технологического и экономического развития стран-лидеров. Вместе с тем каждая модернизация имеет ограничение во времени, проектную логику и определенного субъекта и выгодоприобретателя.

Существуют два основних подхода, в контексте которых воспринимается и оценивается процесс модернизации: линеарно-стадиональный или формационный и цивилизационный. В контексте первого подхода модернизация рассматривается как переход от традиционного, административно-командного общества к современному, либерально-демократическому, а согласно второго, модернизация это спектр возможных изменений, которые в историческом смысле равноправны уже хотя бы по праву своей возможности быть. Модернизация, взятая во временном измерении, представляется как переход от существующего социокультурного состояния к другому, а определенные универсальным линеарним развитием или «избранные» формы бытия осознаются как что-то гарантированное. Во втором случае, то, что мы куда-то движемся - факт, только неизвестно, станет ли фактом то, что мы куда-то придем и придем ли вообще. Переход, как возможная смена форм и способов бытия, не гарантует самого бытия. Он ставит его под вопрос, поскольку в самом механизме перехода они «сходятся» в своей непосредственности, а, значит, теряется гарантированность осуществления бытием ${ }^{3}$.

Социокультурная ситуация современного мира характеризируется наличием силового модернизационного поля, которое притягивает и подталкивает другие страны к западной, либерально-демократической модели общественного развития. Считается, что развитые промышленные страны уже апробировали определенную модель перехода от традиционного общества к современному, постмодерному. В соответствии с этим выделяют «передовые», «прогрессивные» общества, и те, что им подражают, а саму модернизацию рассматривают как взаимодействие цивилизаций, осознанное копирование западных обществ, выступающих в качестве «стран-образцов», а иногда-как синоним вестернизации или американизации. Результаты модернизационных процессов в этих странах свидетельствуют, что догоняющая модель иногда способствует закреплению подчиненного положения незападных стран на мировом рынке, приводит к разрушению традиционных ценностей без полноценной замены их новыми, подрыву социокультурной основы общества.

Практическая несостоятельность данного подхода привела к необходимости переосмысления теорий модернизации, основанных на идее универсализма и

\footnotetext{
${ }^{2}$ В. М. Межуев, Ценности современности в контексте модернизации и глобализации.

${ }^{3}$ М.О. Зайцев, Модернізація і проблеми національної ідентичності // Україна в контексті євроінтеграції: Матеріали Міжнародної науково-теоретичної конференції. - Наукове видання. - Суми: Вид-во СумДУ, 2005, с. 64.
} 
приоритета западной модели. В итоге уже в 70-90-е годы XX столетия концепции развития и модернизации были пересмотрены. Более детально стали исследоваться конкретные модернизационные процессы с учетом специфических исторических и национальных условий, культурного своеобразия стран. Приоритетной целью модернизации было названо изменение социально-экономических и политических структур, которое могло бы проводиться и вне западной модели. Появляются концепции «частичной модернизации», «тупиковой модернизации», «кризисного синдрома модернизации». В рамках этих концепций не отрицается универсальность общественного и политического развития. Вместе с тем принцип универсализма сочетается с партикуляризмом, а их синтез рассматривается как залог успеха модернизационного процесса. Заметим, что в новейших теориях мера такого наследования уже не рассматривается как полное копирование опыта Запада, но определяется осуществлением ряда обязательных мероприятий при сохранении весомой национальной специфики.

Российский исследователь проблем модернизации В. Межуев, указывая на главный изъян модернизации - ее репрессивный и унижающий национальное достоинство характер, считает, что модернизация исчерпала себя не только по форме, но и по существу - как способ перехода от традиционного общества к современному. Ведь современность отождествляется в ней с индустриальной фазой общественного развития, а сегодня эта фаза сменяется другой, как бы ее ни называли - постиндустриализмом, информационализмом, глобализмом и пр. Мир переживает переход к тому, что имеет много названий, но пока не получило однозначного определения. Но ясно одно: этот переход сопровождается кризисом всех форм идентичности, известных до сих пор, кризисом всех модернизаторских идеологий эпохи индустриализма - от либеральной до социалистической. С какой системой идей и ценностей вынужден будет идентифицировать себя человек эпохи постмодерна (или позднего модерна) - вопрос открытый и не имеющий пока общепризнанного решения ${ }^{4}$.

Поскольку модернизация не произошла одновременно во всех странах, то вследствие этого учёные говорят о лидирующих странах и странах с догоняющим типом модернизации. Обычно догоняющая модернизация создает анклавы современной жизни, например крупные города, подобные Сан-Паулу и Рио-деЖанейро в Бразилии, Москве и Санкт-Петербургу в России, существенно отличающиеся от провинции и образом жизни, и состоянием сознания. Такая анклавная модернизация, ломая традиции, ставит общество перед отсутствием перспективы. Она создает очевидное неравенство, обещая равные шансы (чего не делало традиционное общество), но поскольку реально эти шансы не для всех, то растет социальное недовольство.

Проблемы стран, ставших на путь самостоятельного развития, состоят в том, чтобы эффективнее, экономичнее и рациональнее применить модернизационную модель, перенести ее на национальную почву за счет сочетания собственных традиций и ресурсов и определенной внешней помощи. Теперь «эталонный» подход к модернизации вытеснен взглядами на модернизацию как на национальный проект,

${ }^{4}$ B. М. Межуев, op. cit. 
осуществляемый странами ради уменьшения неравномерности уровней развития и как на средство преодоления исторического отставания. Общая тенденция состоит в замене политико-центрической модели на культуроцентрическую, развивающую идею модернизации с опорой на собственные традиции и ценности. В. Федотова предлагает называть ее постмодернизацией, которая, как она полагает, не снимает противоречия институционального и культурного характера в ходе ее проведения 5 .

Глобализация и модернизация обусловили во всем мире процесс преобразования ценностных оснований идентичности, они снижают способность как отдельных общностей, так и индивидов к сохранению базовых ценностей. Российский ученый Л. Блохин, исследуя традиционные экосоциальные системы на примере стран Западной Африки, отмечает: «Достаточно долгое время считалось самоочевидным, что требования модернизации состоят в замене традиционных социальноэкономических структур и технических средств теми, которые сложились и используются в Европе». Отвечая на вопрос «Что такое модернизация?», ученый раскрывает ее сущность следующим образом: «Модернизация - это не просто изменения, отвечающие современным требованиям, а изменения, диктуемые извне, со стороны внешней среды, поскольку изменения, вызванные внутренними причинами, называют развитием». То есть при насильственной модернизации или ситуации, которая диктует модернизацию, происходят грубые изменения матрицы культуры ${ }^{6}$.

В результате противоречия процессов модернизации оказались противоречиями имитации и подражания опыту Запада. Вместо модернизированности наблюдается распад национальной традиционной культуры и неспособность сформировать новую, а процесс модернизации аграрных обществ носил поверхностный и анклавный характер. Заявленные цели не были достигнуты, а стратегия догоняющей модернизации оказалась неэффективной во многом из-за того, что сущность этого процесса осталась за пределами теоретической рефлексии, уступив место редукционизму. Любые модернизационные преобразования предполагают учет социокультурных особенностей трансформирующегося общества.

Украинское общество никогда не отвечало модерным нормам разумного существования. С провозглашением независимости перед Украиной открылись широкие возможности для всеохватывающей модернизации её общества с учетом мирового опыта и реализации собственного социокультурного потенциала. Осуществление системной модернизации всего комплекса отношений и институтов - государства, экономики, общества является сегодня стратегическим направлением, интегральной характеристикой всех изменений и реформ.

Модернизация для Украины - это единственный способ и исторический шанс преодолеть свое отставание. Она возникает не только как задача социокультурных и политико-экономических реформ соответственно вызовам времени, но и как ряд нерешенных проблем, связанных с поисками национальной идентичности. При этом

\footnotetext{
${ }^{5}$ В. Г. Федотова, Плюсы и минусы модели «догоняющей модернизации» // Модернизация и национальные культуры.- М.: Горбачев-фонд, 1995 с. 65-70.

${ }^{6}$ Л.Ф. Блохин, Традиционные экосоциальные системы как основа устойчивого развития в тропиках (на примере Западной Африки) // Человек: образ и сущность (гуманитарные аспекты). Биосфера, ноосфера и экология. Ежегодник ИНИОН РАН. - М., 1999, с. 57.
} 
вопрос стоит не только в плоскости «Кто мы есть?», но и в аспекте «Будем ли мы у своей тождественности вообще?». Ведь за годы независимости украинцы так и не решили проблемы собственной идентичности. А ведь энергетика государства определяется прежде всего энергетикой нации.

Последние события в Украине в контексте социальной эволюции выглядят как начало существенной трансформации общества, как этап его модернизации или европеизации. С достижениями определенного стартового уровня для модернизации, Украина, вследствие разрыва между желаемыми последствиями изменений и реальными их результатами, оказалась в ситуации, известной в науке как «синдром модернизации». Речь идет прежде всего о противоречиях политики доганяющей модернизации. Если процесс либерализации экономики есть системным звеном мирового экономического процесса, а поэтому не исключает элементов глобальной стандартизации, то модернизация общества предусматривает принципиально иную конфигурацию реформ. Модернизированное общество возможно лишь тогда, когда оно утверждается на собственной основе, опирается на национальную идентичность, духовные и культурные ценности своего народа, реализует основной принцип - «быть самим собой».

В этой связи четко вырисовываются три позиции. Во-первых, движение общества по заранее заданной траектории, по наработанным кем-то и навязанным извне схемам и моделям противоречит целям возрождения национальной идентичности, утверждения собственного «Я», ведет к интеллектуальной деградации общества, опустошению личности. Человек перестает быть субъектом здравого смысла, его общественные ожидания и оценночные суждения строятся не на основе собственных ощущений и реального опыта, а путем механического сопоставления, безальтернативной аксиомы: мол, «а у них это делается подругому...».

Во-вторых, на основе идеологии и принципов догоняющей модернизации деформуется политическая система общества, она становится однополярно ориентированной. Создается ситуация «придушенного плюрализма», тогда как действительный плюрализм взглядов как основа демократии практически исключается. Односторонне, искаженно интерпретируется историческая миссия народа, его роль в определении судьбы своей страны, в процесах государственного строительства. Трансформационный процесс все более и более выступает не столько как способ самореализации народа, его жизнь в собственной истории с ее коллизиями и противоречиями, сколько как механическое воплощение заимствованных ценностей.

В-третьих, следствием идеологии догоняющей модернизации становится деградация реформаторской элиты. Стремясь любой ценой утвердить в собственной стране чужие стандарты (западные или восточные, не имеет значения), она денационализируется, становится космополитической, виртуальной. Непоследовательность украинской национально-демократической элиты объясняется в значительной мере именно этим. Представители нашей элиты, прикрываясь громкими фразами реформаторства, на деле превратились в проводников воли доноров, послушных первоклассников, которые воспринимают все рекомендации извне за чистую монету. Отсюда настойчивое желание сменить свою идентичность, уподобиться тем, кто служит для нее образцом. Свою 
общественную миссию украинский правящий класс видит в том, чтобы внедрить заимствованную извне новую идентичность в сознание масс. Собственно, это и есть, по его мнению, модернизация ${ }^{7}$. Новые технологии не изменят общество сами по себе. Пока мир постоянно модернизируется, немодерные элиты обречены существовать в глубоком кризисе. А без модернизации страны говорить о демократии в ней невозможно и безнадежно

Необходимо осознать, что проблемы, перед решением которых Украина остановилась в своем развитии, не сводятся исключительно к экономическим. Это проблемы более системного порядка - проблемы несформированности украинского общества. Экономические преобразования теряют какой-либо смысл, если не связываются с системным обновлением общества в целом. Модернизируя экономику, мы тем самым модернизируем и общество - таким должно быть основное кредо провозглашенной ныне политики реформ. Не уменьшая значение задач экономического развития, все же считаем, что реформирование экономических отношений, обеспечение их стабильно сбалансированной динамики, как и придание принципиально новых импульсов социальным преобразованиям, возможны лишь на качественно новой основе - на основе мировоззренческой консолидации украинского общества, его осовременивания, модернизации, утверджения либеральных ценностей развития и демократии. Иных путей системной модернизации украинского общества не существует.

Основные задачи украинской модернизации лежат вовсе не в техногенной сфере и заключаются отнюдь не в компьютеризации школ, не в строительстве разнообразных «биоагроэкополисов» и даже не в ускоренном развитии нанотехнологий. Главное назначение украинской модернизации - это создание современного общества, современных социальных институтов и инфраструктуры, восстановление сознания своей «современности», формирование гражданинапатриота с инновационным мировоззрением, мышлением, культурой. Результирующая цель модернизации - обеспечение конкурентоспособности Украины как государства и нации ${ }^{8}$.

Украинцам необходимо чрезвычайно быстрыми темпами пройти этапы социальной эволюции, перехода от средневекового государства к модерному, национально-правовому государству, которые Европа и Запад вообще переживали в течение многих десятилетий. Речь идет о попытке приобщиться к модерному миру, где власть ограничена правом, где существует по крайней мере разделение власти, реализуется принцип независимости законодательной, исполнительной и судебной ветвей власти. Известный социальный философ Ю. Хабермас справедливо отмечает, что в постсоветских странах состоялась «рефеодализация». Коррупция и беззаконие, свойственные украинскому обществу, подтверждают существование домодерного, «феодального» строя, который был восстановлен после неудачной коммунистической модернизации. Однако не существует никакой гарантии успешности нынешней модернизации. В настоящий момент внутренние и внешние

${ }^{7}$ А. С. Гальчинський, Лібералізм: уроки для України: наук.-попул. есе. - К.: Либідь, 2011, с. 198-200.

${ }^{8}$ Ibidem, c. $183-189$. 
факторы могут остановить становление правового государства, вернуть страну в предыдущее состояние?.

Реформы должны оправдываться естественным желанием украинцев что-то изменить, улучшить, усовершенствовать в своей жизни, оставаясь при этом самими собой, сохраняя свою самобытность, а вместо с тем и стремлением стать во многом другими, избавиться от чувства своей ущербности и неполноценности, возникающего при сравнении с другими, развитыми, странами и народами. Понятно, что реформы, идущие вразрез с образом жизни и менталитетом украинцев, будуть носить только принудительный характер.

Акцентируем внимание на этом, чтобы подчеркнуть органическую связь четырех взаимосвязанных процессов: 1) выработка национальной идеи, которая должна заполнить существующий мировоззренческий вакуум и стать способом решения экзистенциальных вопросов существования украинской нации, важнейшей основой консолидации украинского общества, придать ему новые импульсы самоутверждения; 2) формирование дееспособной, конструктивной в своих стремлениях национальной элиты. Она должна опираться прежде всего на исторические достижения и устремления украинского народа, на духовную суверенность нации, ее извечные идеалы; 3) развитие и рост экономики должны определяться креативным потенциалом общества. Общество - это прежде всего духовное единение людей на уровне мировоззренческих ценностей, общего видения перспективы. Это построенная на доверии система устойчивых социальнокоммуникационных связей и, наконец, способность создавать максимально благоприятные условия для самореализации энергетических возможностей каждой личности и нации в целом; 4) осуществление инновационной модернизации, под которой мы понимаем продуктивное скачкообразное технологическое, хозяйственное, социально-политическое и гуманитарное обновление украинского общества и украинцев на основе модели опережающего, а не догоняющего развития, на основе проактивной и инициативной стратегии, а не реактивной тактики ${ }^{10}$.

Исторический момент не оставляет украинскому обществу иных вариантов, кроме как стремиться к реализации именно этого проекта. Нужно прекратить неуправляемые процессы десуверенизации, бегство пассионарных элит вместе с большинством граждан во внешнюю и внутреннюю эмиграцию. Псевдодемократизация, ощутимое падение уровня образования, манипуляции с собственной историей, коррупция и проблемы верховенства права могут не оставить нам шансов на европейский «модернизационный рывок».

В своих модернизационных устремлениях Украина не противостоит ни Европе, ни России. В действительности она противостоит возможности собственного небытия, своего социокультурного «угасания». Интеграция Украины в Европу - это

${ }^{9}$ Р. Гривинский, «За последние месяцы мы прошли этапы социальной эволюции, которые Запад переживал в течение многих десятилетий» // День. - 7-8 марта 2014, c. 10 .

${ }^{10}$ А. Н. Окара, Новая идея для новой Украины // День. - 2010. - 9 июня, с.4. 
не просто стратегическая цель, а значительно больше - это воссоздание нашей идентичнсти, возвращение собственного «Я», это основа нашей суверенности и независимости. Но нужно помнить, что евроинтеграция - это не только желание стать членом ЕС, а прежде всего трансформация украинского общества на европейских началах и ценностях.

Отождествление модернизации с вестернизацией, т. е. развития по западным образцам, или тезис о принципиальной непригодности для Украины как культуры модернити, так и всего опыта западного развития, часто мешает снять идеологические шоры и взглянуть на проблему развития Украины критическим взглядом, позволяющем сформулировать новые альтернативы, подчеркивающие самобытность культуры Украины и ее значение для мировой цивилизации в целом, новую философию постмодернизации в целом. Это означает отказ от ложных альтернатив изоляционизма или слияния с Западом и предполагает прежде всего опору на собственные силы, эндогенные предпосылки модернизации.

Любые модернизационные преобразования предполагают учет социокультурных особенностей трансформирующегося общества. Украинское общество также имеет собственную модернизационную специфику. Однако многие из этих особенностей (первостепенная роль государства при осуществлении модернизации, пагубные социальные последствия модернизации для значительной части населения, циклический ее характер в виде последовательного процесса скачков-отступлений), в той или иной степени позволявшие решать задачи индустриальной модернизации, оказываются неадекватными при осуществлении постиндустриальной модернизации. Постиндустриальное общество предполагает горизонтально-сетевой тип организации экономики, что требует взаимодействия множества независимых хозяйственных субъектов; постиндустриальное общество представляет собой ассоциацию автономных личностей с преимущественно постматериалистической системой ценностей, что требует развития институтов гражданского общества и достижения стандартов общества массового потребления для большей части населения.

В то же время отказ от осуществления постиндустриальной модернизации делает в перспективе невозможным сокращение разрыва между Украиной и странами, уже вступившими в стадию постиндустриального развития. В этих условия необходимо осознание нашими административными и интеллектуальными элитами необходимости осуществления проекта постиндустриальной модернизации, достижения консолидации государства и общества на этой основе.

Ведь одна из реальных гуманитарных опасностей в Украине - это отсутствие воли к развитию, маргинальность рефлексий на стратегические темы и смысловая девальвация модернизационно-инновационной риторики, включая разговоры о «человеческом капитале», «экономике знаний» и «прорывном инновационном развитии» и т. д. Сегодня фактически отсутствует детально разработанная программа долгосрочного развития Украины в соответствии с постиндустриальными трендами. Контрмодернизационно настроенные политические элиты и государственная бюрократия, присваивающие «административную» и разные экспортные ренты, в украинских условиях способны нивелировать и «заговорить» какую-либо модернизационную проблематику. Остановка же Украины на этом пути продолжит ее историю буферной зоны. Она 
будет оставаться территорией игры и влияния без достаточных сил и решимости начать собственный проект национальной модернизации. Сегодняшний исторический момент не оставляет украинскому обществу иных вариантов, кроме как стремиться к реализации данного проекта. Продолжительный исторический национальный кризис обязывает к решительным действиям.

Переориентация интересов и целей политики модернизации с вестернизации на национальные ценности, развитие духовности и есть единственный способ возвращения в современность, обретения идентичности, соответствующей реалиям глобализирующегося мира. Успешная инновационная модернизация прорывного (недогоняющего) типа на основе широкой солидарности и баланса сил-между властью, амбициозными группами населения, включая представителей бизнеса, и народом - проводимая с опорой на этические нормы и «миростроительные» ценности христианской цивилизации, способна стать вкладом Украины в теорию и практику современного развития, а также может оказаться важнейшей предпосылкой для «украинского чуда» - трамплином в сообщество если не лидеров развития, то хотя бы не-аутсайдеров. На исторических изломах лидерство может перехватить тот, кто станет проектантом и «дизайнером» общемирового будущего, кто первым заявит новые смыслы и ценности начинающейся эпохи. Не повторять и копировать то, что уже пройдено другими, а вместе с ними участвовать в созидании нового мира - лишь только так можно преодолеть поразивший нас кризис и наверстать упущенное, заявить о себе как о развитой стране XXI века и сохранить себя в глобальном мире.

\section{ЛИТЕРАТУРА:}

[1] Межуев В. М. Ценности современности в контексте модернизации и глобализации // Информационный гуманитарный портал "Знание. Понимание. Умение" - 2009. - №1 - Философия. Политология.

[2] Зайцев М.О. Модернізація і проблеми національної ідентичності // Україна в контексті євроінтеграції: Матеріали Міжнародної науковотеоретичної конференції. - Наукове видання. - Суми: Вид-во СумДУ, 2005.

[3] Федотова В. Г. Плюсы и минусы модели «догоняющей модернизации» // Модернизация и национальные культуры.- М.: Горбачев-фонд, 1995.

[4] Блохин Л.Ф. Традиционные экосоциальные системы как основа устойчивого развития в тропиках (на примере Западной Африки) // Человек: образ и сущность (гуманитарные аспекты). Биосфера, ноосфера и экология. Ежегодник ИНИОН РАН. - М., 1999.

[5] Гальчинський А. С. Лібералізм: уроки для України: наук.-попул. есе. К.: Либідь, 2011.

[6] Гривинский Р. «За последние месяцы мы прошли этапы социальной эволюции, которые Запад переживал в течение многих десятилетий» // День. - 7-8 марта 2014.

[7] Окара А. Н. Новая идея для новой Украины // День. - 2010. - 9 июня. 


\section{MODERNIZATION OF UKRAINIAN SOCIETY AS A SOCIAL EVOLUTION IMPERATIVE}

The article studies the phenomenon of modernization as a large-scale process of transition from a traditional society to the modern and post-industrial society, assuming full or partial reconstruction of the social system in order to accelerate development; as a set of interrelated economic, political, social and cultural spheres of public life, modernization transformation manifests itself in the form of new values and norms of the disappearance of the old. The article characterizes two main types of modernization - organic and inorganic, with each having a time limit, design logic and certain subject and beneficiary, as well as two main approaches in the context of which is perceived and valued the process of modernization: linear-stage (formational) and civilization. It is proved that socio-cultural situation of the contemporary world is characterized by a force of modernization field that attracts and encourages other nations to the liberal democratic model of social development.

The components of the modern Ukraine modernization paradigm are disclosed, the author proves the need to reorient Ukrainian modernization project European values while preserving national specificities, incorporate sociocultural features of a transformed society. The main purpose of the modernization of Ukrainian - is the creation of a modern society, modern social institutions and infrastructure, restoring consciousness of "modernity", the formation of citizen-patriot with an innovative outlook, mindset and culture. It is concluded that the problems before deciding which Ukraine stopped in its development cannot be reduced solely to economic; this problem more systematic order - problems unformed Ukrainian society. Therefore, the reform of economic relations, ensuring their stable balanced dynamics, as well as giving new impulses fundamentally social transformations are only possible on a new basis - on the basis of ideological consolidation of Ukrainian society, its contemporization, modernization, liberal values that have been approved and the development of democracy.

Keywords: national values, modernization, catching up modernization, globalization, identity, cultural identity, national identity, Ukrainian society

\section{MODERNIZACJA SPOŁECZEŃSTWA UKRAIŃSKIEGO JAKO IMPERATYW EWOLUCJI SPOŁECZNEJ}

Autor omawia fenomen modernizacji jako makroproces przejścia od społeczeństwa tradycyjnego do nowoczesnego i postindustrialnego, ktory przewiduje całkowitą albo częściową modernizację systemu społecznego w celu przyśpieszenia rozwoju; jako kompleks powiązanych ze sobą sfer życia społecznego, ekonomicznego, politycznego i kulturowego.

Autor wskazuje, że sytuacja socjalno-kulturowa współczesnego świata jest nacechowana obecnością pola sił modernizacyjnych, które pociąga i popycha inne państwa do modelu liberalno-demokratycznego w rozwoju społeczym.

Badacz ukazuje składowe paradygmatu modernizacyjnego współczesnej Ukrainy, udowadnia konieczność zmiany orientacji na wartości europejskie ale z zachowaniem specyfiki narodowej oraz socjokulturowych osobliwości procesu transformacyjnego. Główne zadanie modernizacji ukraińskiej polega na stworzeniu współczesnego społeczeństwa, współczesnych instytutów społecznych i infrastruktury, odbudowie świadomości swej ,,współczesności”, kształtowaniu współczesnego obywatela - patrioty z innowacyjnym światopoglądem, myśleniem, kulturą. Autor dochodzi do wniosku, że problemy, przed którymi stoi Ukraina, nie sprowadzają się do problemów ekonomicznych. Jest to problem o charakterze systemowym, dlatego reformowanie stosunków ekonomicznych, zabezpieczenie ich stabilnej dynamiki, jak i nadanie zasadniczo nowych impulsów zmianom socjalnym jest możliwe jedynie na jakościowo nowej podstawie - na 
podstawie światopoglądowej konsolidacji społeczeństwa ukraińśkiego, jego uwspółcześnienia, modernizacji, umocnienia liberalnych warości rozwoju i demokracji. Słowa kluczowe: warości narodowe, modernizacja, modernizacja opóźniona, globalizacja, tożsamość, tożsamość kulturowa, tożsamość kulturowa społeczeństwa ukraińskiego.

DOI:10.7862/rz.2014.hss.22

Przesłano do redakcji: maj 2014

Przyjęto do druku: lipiec 2014 